UNIVERSITY OF GOTHENBURG SCHOOL OF BUSINESS, ECONOMICS AND LAW

WORKING PAPERS IN ECONOMICS

No 570

\title{
Adult Mortality, AIDS and Fertility in Rural Malawi
}

Dick Durevall and Annika Lindskog

August 2013

ISSN 1403-2473 (print)

ISSN 1403-2465 (online) 


\title{
Adult Mortality, AIDS and Fertility in Rural Malawi*
}

\author{
Dick Durevall and Annika Lindskog \\ Department of Economics, School of Business, Economics and Law \\ and Gothenburg Centre for Globalization and Development, \\ University of Gothenburg
}

\begin{abstract}
The impact of HIV/AIDS on fertility in sub-Saharan Africa has received attention recently, since changes in population structure can impact on future economic development. We analyze the effect of AIDS on actual and desired fertility in rural Malawi, using data from Malawi 2004 Demographic and Health Survey and population censuses. Since AIDS was the dominating cause of death during the 1990s and early 2000s, we use prime-age adult mortality as the key explanatory variable. The focus is on heterogeneity in the response of gender-specific mortality rates. By estimating ordered probit models we show that actual fertility responds positively to male mortality but negatively to female mortality, and that the overall fertility response is positive but small. One interpretation of the findings is that the effects of female and male mortality differ because of an old-age security motive for having children. When a woman risks death before her children grow up, she is less likely to need support of children and demand should be low, but when the risk of husband's death is high, the woman should expect to rely more on children's support.
\end{abstract}

Keywords: AIDS, demand for children, fertility, HIV, adult mortality, old age security.

JEL classification: I10, J13, O12

*This paper is a heavy revision of SWOPEC No 369: How Does Communal HIV/AIDS Affect Fertility? - Evidence from Malawi 


\section{INTRODUCTION}

The number of youths is increasing rapidly in most sub-Saharan African countries, implying that changes in fertility is having a strong impact on population growth, dependency ratios, and the number of new entrants to the labor market, all of which affect economic growth and development. Since HIV prevalence is high in many sub-Saharan countries, the fertility response is likely to be a key determinant of the future course of their economies (Young, 2005, 2007). Several studies have therefore analyzed the relationship between HIV/AIDS and fertility in sub-Saharan Africa, but the findings vary and the overall result is inconclusive. ${ }^{1} \mathrm{~A}$ possible explanation for the inconclusive result is that the fertility response is heterogeneous, an issue that has received little attention. ${ }^{2}$

The purpose of this paper is to analyze one type of heterogeneity in the fertility response, mortality differences among prime-age men versus women, by estimating the impact of (primarily) AIDS-induced mortality on both actual fertility and women's and men's desired fertility in Malawi. The spread of AIDS increased prime-age mortality in Malawi rapidly, and in the late 1990s it accounted for approximately $75 \%$ of all deaths (Doctor and Weinreb, 2003), so prime-age mortality should be a good indicator of AIDS.

We estimate ordered probit models, using data from the 2004 Malawi Demographic and Health Survey (MDHS) and population censuses. Fertility is measured by the number of children women gave birth to between 1999 and 2004, so the findings are not affected by the

\footnotetext{
1 There is ample evidence that HIV infected women in sub-Saharan Africa is $20 \%$ to $40 \%$ less fertile than uninfected women (Lewis et al., 2004). However, the findings for the overall population vary greatly: Young $(2005,2007)$ and Boucekkine et al. (2009) find a substantial negative effect on fertility; Lorentzen et al. (2008) and Kalemli-Ozcan and Turan (2011) find a positive effect; Kalemli-Ozcan (2012) finds both a positive and a negative effect depending on the specification of the model and the data used; Durevall and Lindskog (2011) find a negligible negative effect; Ahuja et al. (2009) and Fortson (2009) find no effect; while Juhn et al. (2009), find a negative effect among HIV positive women but none among the others.

${ }^{2}$ Two exceptions are Durevall and Lindskog (2011) and Fink and Linnemayr (2009) who analyse differences in fertility response over the reproductive life cycle and in women's level of education, respectively.
} 
distribution of antiretroviral drugs. ${ }^{3}$ We restrict the analysis to rural Malawi both because the insurance motive for having children is likely to be more important there than in urban areas, and because AIDS was uncommon in the rural areas until the mid-1980s (UNGASS, 2010), allowing us to control for pre-AIDS fertility rates.

We also restrict the sample to those who are HIV negative to avoid mixing up behavioral and physiological effects. As a result, our sample is not representative of all rural Malawians as the fertility behavior of women who remain uninfected might differ from that of women who become infected. Moreover, the women who consented to be HIV tested might differ from those who refused. Nonetheless, our sample should be representative for the overwhelming majority; about $90 \%$ are uninfected and about $80 \%$ consented to the HIV test, and $85 \%$ of Malawi's population lives in rural areas (NSO, 2010a).define rural in footnote

There is a paucity of data on AIDS cases, so we use prime-age mortality, following Ueyama and Yamauchi (2009) who also use prime-age mortality as a proxy for AIDS in a study on marriage behavior. In the ideal case we would have used an instrument for AIDS-induced mortality since HIV has not spread randomly across Malawi, but it is difficult to find a credible one. We avoid the problem of simultaneity bias by using lagged district prime-age mortality rates, obtained from the 1998 Population Census. Moreover, as HIV might have spread rapidly in districts that had high fertility rates, we include district fertility in 1987 in the regressions to control for factors that affected fertility before mortality in AIDS became common in the rural areas.

Our main findings show that prime-age mortality, and thus AIDS, increases fertility among HIV-negative women; it contributed to a ten percent increase during the period analyzed, mid-1999 - mid-2004, but this effect is statistically weak and a 95\% confidence interval

\footnotetext{
${ }^{3}$ Very few had access to antiretroviral drugs before public distribution was rolled out, and by early 2004 only 3000 people had initiated treatment, including public and private sectors (Malawi Government, 2012).
} 
includes zero and negative values. In addition, when the model is estimated with the whole sample, including HIV-positive women and those who refused to be tested, the impact is close to zero and insignificant. Thus, we fail to find support for the hypotheses that AIDS either sharply reduces or increases fertility at population level.

The statistically weak overall effect appears to be due to heterogeneity: Female mortality has a negative effect on actual fertility, while male mortality has a positive, and larger, effect. An increase in female mortality from its mean in 1987 to its mean in 1998 is predicted to decrease the average number of births $1999-2004$ by $6.3 \%$ ( 0.056 children), while a similar increase in male mortality is predicted to increase births by $18.5 \%$ ( 0.165 children).

Further study is required to fully understand the findings. However, one interpretation is that concern with insurance and old-age support has a strong influence the fertility response, particularly for women (Cain, 1981; Nugent, 1985; Pörtner, 2001). When female mortality is high, as during the AIDS epidemic, they might not expect to live to old age, and there is less need for children. However, when male mortality is high there is a high probability that the husband dies before the wife, increasing the need of insurance and old-age support for the woman. The fertility response to increased female mortality can therefore differ from that of increased male mortality.

The following section outlines various mechanisms through which HIV/AIDS might impact on fertility and briefly reviews earlier studies on sub-Saharan Africa. Section 3 describes the recent development of fertility and HIV/AIDS in Malawi. Section 4 presents the empirical model, and Section 5 describes the data. Section 6 reports the results from the empirical analysis, and Section 7 discusses the findings and draws conclusions. 


\section{THEORY AND EVIDENCE ON HIVIAIDS AND FERTILITY}

In this section we first outline the relationship between HIV/AIDS and actual and desired fertility, and then we briefly review recent empirical studies on HIV/AIDS and fertility in sub-Saharan Africa.

\subsection{How does HIVIAIDS affect fertility?}

HIV/AIDS might affect fertility in numerous ways with no single theory embracing them all. As a heuristic device, the effects can be collected into three groups: direct physiological effects; changes in behavior to reduce the risk of HIV infection; and changes in desired number of children (i.e., preferences) for both HIV-positive and HIV-negative women and men.

The physiological channel works through several mechanisms. Among the most important ones are: higher rates of miscarriage and stillbirth; co-infection with other sexually transmitted diseases; weight loss leading to amenorrhea; and reduced frequency of intercourse because of illness and premature death of regular partner. They all point towards reduced fertility among HIV-infected women, mainly among those who have developed AIDS. Fertility among HIV-infected women is estimated to be $20 \%$ to $40 \%$ less than for uninfected women, but we cannot be sure that this difference is only due to physiological effects (Lewis et al., 2004; Juhn et al., 2009).

The risk of HIV infection increases the expected cost of sexual contact, particularly of risky sexual behavior. Thus we should expect to see behavioral change, i.e. fewer concurrent partners, less extra marital sex, increased abstinence, delayed age at sexual debut, and increased condom use, which could translate into lower fertility. There is an ongoing debate about the nature and extent of changes in sexual behavior induced by the HIV epidemic, but 
it appears to have been limited in most African societies when considering the severity of the epidemic (Glick and Sahn, 2008; Oster, 2012).

A response that would reduce the risk of infection is to marry and establish a (hopefully) monogamous relationship early. Ueyama and Yamauchi (2009) find that Malawian women marry earlier the higher the prime-age mortality. Women might marry young voluntarily, but it could also be that men have more bargaining power on the marriage market and decide to marry younger wives, less likely to be HIV positive. Another possible explanation is pressure on orphans to leave foster families, In Malawi, roughly $18 \%$ of the children, or 1.1 million, are considered to be orphans (UNGASS, 2010). In any case, the fertility effect of earlier marriage is that women start childbearing earlier.

Parents might also wish to avoid giving birth to HIV-infected babies, who would die at an early age without anti-retroviral therapy (Young, 2005; 2007). It is thus possible that some women, instead of abstaining from having children, have them earlier, when they have a smaller probability of being HIV positive. In a qualitative study, Zimbabwean women mention the possibility of both decreasing the number of births and giving birth earlier as responses to the risk of giving birth to HIV-infected babies (Grieser et al., 2001).

There is a sizeable literature on child mortality and fertility mostly pointing towards a positive relationship (Schultz, 1997). AIDS raises child mortality, but in Malawi under-five mortality has dropped sharply in the midst of the epidemic, from 218 per 1,000 births in 1990 to 110 in 2009 (UNICEF, 2010). ${ }^{4}$ Child mortality could still be higher than it would have been without AIDS, with implications for fertility. However, the effect of AIDS-induced

\footnotetext{
${ }^{4}$ Child mortality declined because other factors dominated over AIDS, including increased immunization, vitamin A supplementation, and exclusive breastfeeding, and elimination of neonatal tetanus (NSO and UNICEF, 2008).
} 
child mortality on fertility is likely to be small. This does not preclude that the risk of giving birth to HIV-infected babies affects fertility.

One of the most stunning effects of HIV/AIDS is the sharp increase in prime-age mortality: in Malawi it rose fourfold from the 1980s to 2000 according Doctor and Weinreb (2003). According to Soares $(2005 ; 2006)$, adult mortality increases fertility through two mechanisms: First, it reduces returns to education, increasing the relative attractiveness of childbearing, where the two are seen as alternatives. Though Soares focuses on the total number of children, women would also start childbearing earlier if they get married and have children instead of continuing school. Second, parents care about the continued survival of their lineage, or at least evolution implies that they behave as if they do. This means they have more children when children's life expectancy as adults is lower. In the context of HIV/AIDS, the increase in prime-age mortality should thus raise fertility (Lorentzen et al., 2008; Juhn, et al., 2009; Kalemli-Ozcan, 2012).

Young $(2005,2007)$ argues that there is an indirect mechanism working in the opposite direction: HIV leads to lower fertility because mortality-induced wage increases and new job openings raise the opportunity cost of having children. Boucekkine et al. (2009) incorporate this effect in a general equilibrium model of the HIV epidemic that also accounts for adult and child mortality. The authors conclude that there is an ambiguous impact of adult mortality when a negative income effect is allowed for. Hence, the total impact on fertility is also ambiguous and probably context specific.

A potential effect, not included in the models, is the insurance and old-age security motive, which is likely to be a major reason for having children in sub-Saharan countries without oldage pensions, particularly in rural areas (Cain, 1981; Nugent, 1985; Pörtner, 2001; Boldrin et al., 2005). And the existence of substantial intergenerational transfers in Malawi is 
documented by Kohler et al. (2011). In addition to economic security, children are likely to provide care to their parents. Increased death rates of grown-up children thus means that more children are needed to ascertain a given number of survivors. However, HIV/AIDS will also affect parents own mortality risk. When parents expect to die before their children reach adulthood, they have less need of the insurance and old-age security, which reduces the marginal benefit of children. Ainsworth et al. (1998) briefly mention this mechanism in relation to HIV/AIDS, but to our knowledge it has not been further explored in the recent literature. The effect might be strong, since there are indications that the HIV epidemic has raised the subjective own-mortality risk in Malawi much more than the objective risk (Delavande and Kohler, 2009).

Further, the insurance and old-age security motive to have children is likely to be more important for women than men (Cain, 1981; Nugent, 1985). A typical woman is younger than her husband and lives longer, so she outlives him by several years and should expect long periods of widowhood. Moreover, job opportunities are much more limited for women than men, and in rural Malawi they often lack the knowledge to continue with commercial farming when the man dies. Another difference is that women in Malawi often risk losing their property when they become widows because of land grabbing (Arrehag et al., 2006). Thus, female adult mortality, related to women's own mortality risk should reduce women's demand for children. Male adult mortality is instead related to her spouse's risk of death and the expected length of widowhood, increasing the demand for children.

\subsection{Empirical studies on HIV and fertility}

Initially, most studies focused on the fertility response among HIV-positive individuals or on small samples in a few cities (Setel, 1995; Ntozi, 2002; United Nations, 2002). As mentioned, the main finding was that HIV infection reduces fertility, most likely due to physiological 
reasons. The impact on total fertility would be small, however. For example, if about $12.9 \%$ of the women are HIV positive in Malawi, as indicated by Malawi Government (2012), fertility would drop by about $2.5 \%$ to $4.5 \%$. The focus has thus shifted to the response of women in general and the overall impact of HIV/AIDS on fertility.

Several types of approaches and data have been used to estimate the overall impact of HIV/AIDS on fertility in sub-Saharan Africa, but the findings are inconclusive. Using macropanel data over the period 1960-2000, Lorentzen et al. (2008) find that adult mortality is positively associated with high fertility, and conclude that AIDS increases fertility since it increases adult mortality. Kalemli-Ozcan (2012) tests the associations between HIV/AIDS and fertility in sub-Saharan Africa using country and country-regional data and individual data. With cross-country data, she also finds that the disease increases fertility. However, estimates with regional data and fixed effects show a negative or insignificant impact of HIV/AIDS, depending on the specification.

Some studies find that HIV/AIDS has a weak or no effect on fertility. Ahuja et al. (2009) use macro data and circumcision as an instrument to identify the causal impact of HIV/AIDS. Most of the coefficients are negative, but insignificant. Fortson (2009) constructs regional total fertility trends in 12 countries and test for an effect with a difference-in-difference approach, and finds no effect. Magadi and Agwanda (2010) study the effect of communal HIV prevalence on fertility in Kenya using DHS data from 2003 with HIV tests. They fail to find that communal HIV affects actual or desired fertility, but indictors of HIV/AIDS awareness seem to reduce overall fertility. By using DHS data with HIV testing, Juhn et al. (2009) are able to analyze behavioral responses among non-infected women at the countryregional level in 13 sub-Saharan African countries. They find no significant effect. HIV/AIDS reduces fertility due to actual infections, but the overall impact is very small. 
In contrast to these studies, Young (2007), using DHS data from a large sample of subSaharan countries, finds a strong negative effect; a country with a HIV-prevalence rate at $10 \%$ reduces fertility by roughly the same magnitude as moving from no education to secondary education. Young (2005) obtains similar results for South Africa. However, Juhn et al. (2009) and Kalemli-Ozcan and Turan (2011) criticize Young's studies, which use data from before fertility outcomes linked to HIV status were available. For example, when they re-do the analysis on South Africa for the period 1990-1998, for which there is information on HIV rates, HIV increases fertility.

Nonetheless, Boucekkine et al. (2009) estimate dynamic models for 39 sub-Saharan African countries over 1980-2004 and find that adult mortality reduces fertility, while child mortality increases it. They conclude that overall effect of HIV/AIDS is an unambiguous negative effect on net fertility, i.e., the number of surviving children.

The research reviewed has mainly concentrated on the effect on overall fertility. Hence, the failure to find clear-cut behavior responses might be due heterogeneity. There are a few studies that shed light on heterogeneity in age and schooling among women. Noël-Miller (2003), using panel data from three Malawian districts, finds that the association between the degree of worry regarding HIV/AIDS infection and the number of births is positive among young women and negative among older women. Similarly, Durevall and Lindskog (2011), who use a panel with recall data on fertility from Malawi, find that young women give birth to their first child earlier when HIV rates increase, while fertility decreases among older women. Shapira (2010) find similar results in rural Malawi for subjective beliefs on own HIV risk. One study focuses on schooling, Fink and Linnemayr (2009). They use data from five African countries, but not Malawi, and find that better educated women reduce fertility as a response to the HIV epidemic, while less educated women instead increase it. Hence, all 
these studies indicate there might be substantial, but heterogeneous, behavioral changes to HIV/AIDS that might counteract each other.

\section{FERTILITY AND HIVIAIDS IN MALAWI}

In the early 1960 s, the total fertility rate in Malawi was similar to those in other African and other less-developed countries. But while fertility in most other countries fell during 19601980, it grew in Malawi, probably because of the ideology and policy of the Malawian government under President Banda: birth control was seen as incompatible with Malawian culture (Chimbwete et al., 2005). Fertility started to fall in the mid-1980s at a rate similar to that in many other African countries: the total fertility rate declined from 7.6 in 1984, to 7.4 in 1987, and 6.5 in 1998. Nonetheless, it is still high compared to most countries; it hovered between 6.3 and 6.0 from the late 1990s until 2008, but seems to have fallen to 5.7 in 2010 (NSO, 2010b; NSO and ORC Macro, 2011). Still, on average, women in Malawi give birth to one more child than the average African woman (NSO, 2010b).

Malawi's first AIDS case was diagnosed in 1985, at a time when the national HIV prevalence rate still was low. From then on the epidemic spread rapidly, first in the major cities, and then in rural areas.

Malawi started monitoring HIV prevalence among pregnant women attending antenatal clinics in urban areas in the late 1980 s. Initially the prevalence rate was $2 \%$, but it rose quickly and peaked at $26 \%$ in 1995 , since then it has declined slowly. According to the most recent estimates, $22.7 \%$ of all women residing in urban areas aged $15-49$ are HIV positive. In the rural areas, prevalence rates rose from $6 \%$ among antenatal women in 1992 to $18 \%$ in 1998 (Malawi Government, 2007). In 2010, the rate was 10.5\% among women in general (NSO and OCR Macro, 2011). 
Data on AIDS deaths are more uncertain but UNAIDS has estimated that they rose from about 11,000 in 1990 for the whole of Malawi to 74,000 in 2004. In 2009 they had declined to 51,000 out of a population of 13 million (UNAIDS, 2012). Since the vast majority of the population lives in rural areas, and HIV rates rose quickly first in the 1990s, AIDS deaths must have been rare in rural areas in the 1980s.

HIV and AIDS have thus been prevalent in Malawi for over 25 years. Before the roll-out of antiretroviral treatment AIDS had increased prime-age mortality about four times, i.e., three out of four deaths among prime-age adults were due to AIDS (Doctor and Weinreb, 2003). As a result, knowledge about AIDS is widespread. In fact, already in the MDHS carried out in 1992 , about $90 \%$ of respondents had heard about the disease, rising to $99 \%$ in the 2000 MDHS (NSO and Macro International, 1994; NSO and ORC Macro, 2001). So if HIV/AIDS affects decision-making about childbearing, this should be measurable.

One of the striking features of the epidemic in Malawi (and many other African countries) is its differential impact on men and women: about $60 \%$ of infected adults are women. Furthermore, male and female HIV rates vary widely across districts. For example, in Blantyre (with the most important commercial city), men and women have an equal probability of being HIV positive, while in Zomba (with an important university city), women are twice as likely as men to be HIV positive (NSO and ORC Macro, 2005).

\section{MODEL AND INFERENCE}

When analyzing the effect of the HIV epidemic on fertility, we are ultimately interested in the effect on women's complete fertility, the total number of children given birth, and possibly the timing of those births. However, since the epidemic started in earnest in the mid-1980s, it is too early to study its effects on complete birth histories. Thus, using the approach of Soares (2006), we focus on fertility during the period 1999-2004. Soares studies childbearing up to 
the date of the survey, treated as a function of the woman's individual choice, factors not under her control, and her age. Since we are studying fertility during a limited period, we also use prior births to control for the stage of the reproductive life cycle the woman is in. Furthermore, fertility is allowed to depend on recent information on adult mortality. There is also uncertainty in the model, which captures the fact that women cannot control their fertility perfectly, for biological reasons, such as fecundity, and for social reasons, such as their partner's attitudes.

We assume that the number of births during the study period is a function of $B$, a latent continuous variable that indicates the propensity to have a certain number of births, where $B=N+\varepsilon$, with $N=N(n(X), t, p b)$, and $\varepsilon$ a random term representing uncertainty. Behavior is determined by desired lifetime fertility, $n=n(X)$, where $X$ includes individual and communal factors, by the age of the woman, $t$, and the number of prior births, $p b$. The actual number of births, $N$, during a given period for a woman at a certain age is

$$
\begin{aligned}
& 0 \text { if } B \leq c_{0} ; \\
& \mathrm{k} \text { if } c_{k-1}<B \leq c_{k}, \quad k=1-3 ; \\
& 4 \text { if } c_{3}<B ;
\end{aligned}
$$

where $c_{0}-c_{3}$ are cut-off values and 4 is the maximum number of births observed during the period. We assume that $\varepsilon$ is normally distributed and estimate this as an ordered probit model. ${ }^{5}$ The probability that a women will not give birth to any children during the period is then

$$
\begin{aligned}
P(0) & =P\left(B \leq c_{0}\right) \\
& =P\left(\varepsilon \leq c_{0}-N\right) \\
& =\Phi\left(c_{0}-N\right)
\end{aligned}
$$

\footnotetext{
${ }^{5}$ It is common to use a Poisson model or some other count model to estimate the number of births. However, the Poisson model does not fit the data because of under-dispersion. Moreover, the ordered probit model is closer to our conceptual framework of childbearing. Soares (2006) provides a detailed motivation.
} 
where $\Phi($.$) indicates the standard normal distribution function. The other probabilities can be$ specified as

$$
\begin{aligned}
& P(1)=\Phi\left(c_{1}-N\right)-\Phi\left(c_{0}-N\right) \\
& P(2)=\Phi\left(c_{2}-N\right)-\Phi\left(c_{1}-N\right) \\
& P(3)=\Phi\left(c_{3}-N\right)-\Phi\left(c_{2}-N\right) \\
& P(4)=1-\Phi\left(c_{3}-N\right)
\end{aligned}
$$

The values of $c_{0}-c_{3}$ are estimated as parameters in the model, together with the coefficients in $N=N(n(X), t, p b)$.

Our main explanatory variable, district prime-age mortality, only varies across Malawi's 27 districts. It is, thus, essential to account for within-district dependence in the error term (Moulton, 1990; Bertrand et al., 2004). Within-cluster dependence is usually accounted for with clustered standard errors. However, estimation of clustered standard errors, like other 'sandwich type' standard errors, relies on large-sample asymptotics, and thus requires a large number of clusters for correct inference. We use a procedure proposed by Cameron et al. (2008) for inference with few clusters, the cluster bootstrap-t procedure. ${ }^{6}$

The cluster bootstrap-t procedure works in the following way. In each iteration $j$, the bootstrap randomly samples, with replacement, the number of clusters in the original sample. Thereafter the regression model is run, and the Wald-statistic $w_{b}^{*}=\left(\hat{\beta}_{j, b}^{*}-\hat{\beta}_{b}\right) / s_{\hat{\beta}_{j, b}^{*}}$ is calculated, where $\hat{\beta}_{b}$ is the original sample parameter, $\hat{\beta}_{j, b}^{*}$ is the parameter of the $j$ th iteration, and $s_{\hat{\beta}_{j, b}^{*}}$ is the cluster corrected standard error of the parameter in the $j$ th iteration. The null-hypothesis that the parameter equals zero is then rejected at $\alpha$ level of significance if the original sample Wald-statistic $w$ is either smaller than $W_{[\alpha / 2]}^{*}$ or larger than $W_{[1-\alpha / 2]}^{*}$.

\footnotetext{
${ }^{6}$ They also suggest the wild-bootstrap, which is a modified residual bootstrap. In an ordered probit model it is, however, not appropriate to bootstrap 'residuals'.
} 


\section{DATA AND VARIABLES}

The main source of data is the nationally representative MDHS carried out in 2004, which is before antiretroviral drugs became widely available (Measure DHS, 2004). Apart from fertility-related information and data on a range of characteristics of the respondents and their households, the 2004 MDHS contains HIV status for a subsample, the first nationally representative survey of HIV prevalence.

We focus on rural areas ${ }^{7}$ for two reasons. First, the insurance and old-age security motive for having children is likely to be much stronger in rural than urban areas (Nugent, 1985). Second, HIV was virtually non-existent in rural areas in the mid-1980s (UNGASS, 2010) and thus should not have affected district fertility in 1987, an important control variable to deal with possible endogeneity. In addition, about $85 \%$ of the population in Malawi lives in the rural areas (NSO, 2010a).

Furthermore, we use the sample of knowingly HIV-negative women, i.e. women from whom a negative sero-prevalence blood sample was successfully collected. Although we know that the women are HIV negative, very few of them did at the time, since it was uncommon for people to go for HIV testing before AIDS had developed (Morah, 2007). Thus, we should capture the effects of an uncertain own HIV status on fertility preferences. We restrict the sample to knowingly HIV-negative to avoid mixing up behavioural responses in the general female population with physiological effects among HIV-positive women. A drawback is that our sample is not representative of all women living in rural areas since women who remain uninfected could differ from other women. Still, uninfected women in rural areas make up the vast majority of the Malawian women.

\footnotetext{
${ }^{7}$ Rural area is defined by the National Statistical Office in Malawi. It is all that is not urban area, where urban areas refer to the four major cities of Blantyre, Lilongwe, Mzuzu and Zomba and other urban areas, which consist of Bomas and gazetted town planning areas.
} 
Since only about $80 \%$ of women agreed to do the HIV test, there is a potential sampleselection problem. In the final 2004 MDHS report, the issue of potential response bias is investigated by comparing observed and predicted HIV rates for different groups of people (NSO and ORC Macro, 2005). With the exception of the capital Lilongwe, observed and predicted rates differ little. In any case, since we focus on HIV-negative women, refusal to test among infected women seems unlikely to bias our results.

Our key dependent variable is realised fertility, which we measure as the number of births during the five-year period preceding data collection; i.e. from approximately mid-1999 to mid-2004. ${ }^{8}$ The period was chosen to start after our measurement of mortality, which is for one year prior to the census, carried out in 1998. On average women gave birth to almost one child during the period (see Table A1).

As a complement to estimations on realised fertility, and to provide information about whether changes in realised fertility are related to changes in the desired number of children, we also estimate models with desired fertility as the dependent variable. It is measured by respondents' stated ideal number of children. Women and men were asked how many children they would have liked to have if it was possible to go back in time and choose freely. There is a six-year time-gap between the measures of mortality and desired fertility, which is on the long side. However, we use mortality data that match actual fertility, which is the focus of the study; the desired fertility estimations are compliments.

As with many survey questions of a subjective nature, it is not obvious that all persons understood the question correctly, and it could be biased in favour of the number of children they already have. However, we are interested in differences across women and men, not the actual number. An important difference to realised fertility is that the ideal number of

\footnotetext{
${ }^{8}$ Tables A1 and A2 in Appendix report summary statistics for all variables used in the analysis.
} 
children could be understood as indicating the number of surviving children, not the number of children born. On average both women and men want to have four children (Table A1).

Our measure of mortality is district prime-age mortality rates from the 1998 census, differentiated by gender. ${ }^{9}$ Prime-age mortality is the number of deaths per thousand individuals aged 30 to 49 years during 1997-1998 in rural areas of the district (data provided by the Malawi National Statistical Office). The mean district mortality rate is 17 deaths per 1000, varying from 7 to 36 (Table A2).

There are several advantages with the 1998 prime-age mortality rate as an indicator of HIV/AIDS compared to HIV prevalence based on DHS data, used in several other studies. ${ }^{10}$ First, the mortality data predates the study period, so any feed-back effects from fertility in 1999-2004 to mortality in 1998 are highly improbable. Second, deaths are directly observable, as opposed to HIV status, meaning that people could act on them. Even if people are not aware of precise mortality rates and how these differ between men and women, they are able to observe prime-age adult deaths in their surroundings. People die due to other reasons than AIDS of course, but among prime-age adults in heavily affected countries AIDS was the leading cause of death until public distribution of antiretroviral drugs reached a large part of those eligible (Oster, 2010). In Malawi, this was about 2008-2009 (Malawi Government, 2012). Finally, the census district mortality data should be of reasonably good quality since it is based on many observations.

We avoid the problem of simultaneity bias by using lagged mortality rates. Moreover, we include pre-HIV/AIDS district fertility in regressions, measured by the ratio of the number of

\footnotetext{
${ }^{9}$ The choice of indicator for HIV/AIDS varies in the literature. Some examples are: national HIV-rates obtained from antenatal clinics (Young, 2005, 2007; Kalemli-Ozcan, 2010), district HIV-rates obtained from antenatal clinics (Durevall and Lindskog, 2011), AIDS deaths (Kalemli-Ozcan, 2010), and regional HIV-rates from DHSs (Juhn et al., 2009).

${ }^{10}$ A serious potential drawback in studies using current HIV prevalence rates, such as Juhn et al. (2009) and Magadi and Agwanda (2010) is that women might actually have become infected while getting pregnant.
} 
births to women in reproductive age (15-49) in each district, using data from the 1987 population census since it is possible that high-fertility districts were worse affected by HIV. Including 1987 district fertility in the regressions proves to be important as it changes the sign of the total mortality effect from negative to positive. In this way we control for factors that were time-invariant between 1987 and $1998 .^{11}$

We also control for the woman's age and prior number of births. Age enters our model as seven dummy variables for the age groups 15-19, 20-24, etc., up to 45-49 (and 50-54 for men). Age at the time of the survey is used, with fertility measured during the previous five years. Prior number of births is the total up to the beginning of the five-year period.

Economic theory suggests that income and the opportunity costs of women's time should be important determinants of desired fertility. To capture these variables, household-wealth quintiles (data on income is not collected) and the woman's educational level (no schooling or incomplete primary; complete primary; complete secondary; higher education) are included. If permanent income matters more than current income for fertility, wealth should be a good proxy (Bollen et al., 2007). Unfortunately, information on wealth and education is only available from the survey year. Since less than $10 \%$ of the women had more than 8 years of schooling, most of them had reached their completed level of schooling earlier than 1999, but endogeneity is a potential problem with the youngest group. There could also be endogeneity if there were systematic changes in relative wealth over the previous five years. However, we checked the robustness of our results by estimating models without wealth and education, and there are only marginal differences (not reported). ${ }^{12}$

Norms are likely to influence reproductive and sexual behaviour and thus might affect both the spread of HIV and fertility. We control for norms using dummies for ethnic and religious

\footnotetext{
${ }^{11}$ Districts that had lower fertility before HIV have thus been harder hit by the epidemic than others.

${ }^{12}$ The regression results are available on request.
} 
affiliation. It is hoped that these variables are sufficient to capture key differences in customs of the rural population.

\section{RESULTS}

In this section we first test for the effect of prime-age mortality, measured by aggregated district-level mortality, on overall fertility. Then we test for differences in effects due to gender-specific district mortality (sub-section 6.2). Table A3 in Appendix reports original tvalues and the distribution of cluster bootstrap-t statistics for selected specifications. ${ }^{13}$ (The table is included to provide additional information for referees.)

\subsection{Overall Fertility}

Table 1 reports the effect of district prime-age mortality on fertility (specification 1, 4 and 5), and women's and men's desired fertility (specifications 2 and 3). The null hypothesis of a zero effect of the prime-age mortality on fertility can be rejected in favour of a positive effect, but only at the ten per cent level. The magnitude of the effect of AIDS on fertility is illustrated in Table 2, which presents the predicted number of births per woman if prime-age mortality goes from its mean in 1987 (3.9 deaths per 1,000 aged 30-49) to its mean in 1998 (15.8). With the HIV/AIDS epidemic, a woman in fertile age (15-49) is predicted to give birth to around 0.111 more children during five years. However, this estimate is uncertain since a 95\% confidence interval would include negative values, and when the model is reestimated with all women, i.e., the infected ones and those who were not tested for HIV, the effect of mortality is clearly insignificant (specification 4).

\section{$<<$ TABLE 1 ABOUT HERE $>>$ \\ $<<$ TABLE 2 ABOUT HERE $>>$}

\footnotetext{
${ }^{13}$ Results with standard clustered standard errors are very similar (not reported, but available from the authors). This is probably because with 27 clusters we are at the margin of needing to use bootstrapping.
} 
The positive effect on actual fertility is not matched by a corresponding increase in desired fertility. Instead, mortality is predicted to decrease women's ideal number of children by about 0.37 (specification 2) and men's ideal number of children by about 0.24 (specification 3). And these results are statistically strong; the null hypothesis of no impact of prime-age mortality is rejected at the five per cent level for both women and men.

The variable measuring pre-AIDS district fertility is positively associated with women's fertility in 1999-2004, but not with women's and men's ideal number of children. Interestingly, when we do not control for pre-HIV/AIDS district fertility in the regression with actual fertility, the estimated effect of mortality is negative (specification 5). Districts that had lower fertility before the HIV/AIDS epidemic thus seem to have been worse affected by the epidemic than others. This is at least partially because the more densely populated and poorer Southern Region had lower fertility and more HIV in the 1990s.

The control variables have the expected effects. The coefficients of the age dummies in Table 1 (specification 1) show how age affects fertility non-linearly; it increases to 25-29, and then declines. The larger the number of births before 1999, the larger the probability of giving birth during 1999-2004. This is probably explained by differences in fertility between women that had married and started child-bearing by 1999 and unmarried women.

The effects of age on ideal number of children differ by gender; older women want fewer children than younger women, while older men want more children than younger men. Women and men with more living children also want more children, either because they have acted to fulfil their fertility intentions or because past fertility has changed (stated) fertility preferences.

As usual, education is associated with lower fertility, with a statistically significant difference between those who have less than complete primary education and those who have secondary 
or higher education. Household wealth is also associated with lower fertility, with statistically significant effects for those in the third, fourth and fifth quintiles. This suggests that wealthier families substitute child quality for child quantity, or that the opportunity cost of women's time is higher in wealthier households, even after controlling for their educational level.

To save space we do not report the coefficients of the ethnicity and religion dummies and cutoffs. Moreover, the coefficients of the control variables are not reported in the following estimations; they are not substantially different from those in Table 1. All results are available from the authors on request.

\subsection{Gender-differentiated Effects}

Table 3 shows coefficients from regressions that distinguish between female and male district mortality rates, while Table 4 reports predicted effects on fertility of either female mortality, male mortality, or both, due to an increase from their mean in 1987 to their mean in 1998.

$$
\begin{aligned}
& .<\text { TABLE } 3 \text { ABOUT HERE }>> \\
& <<\text { TABLE } 4 \text { ABOUT HERE }>>
\end{aligned}
$$

Female and male prime-age mortality affects fertility differently. An increase in female mortality from its mean in 1987 to its mean in 1998 is predicted to decrease the average number of births $1999-2004$ by 0.056 children, while a similar increase in male mortality is predicted to increase births with 0.165 . The negative effect of female mortality is significant at the ten per cent level, while the positive effect of male mortality is statistically significant at the five per cent level. The difference between female and male mortality is statistically significant at the five per cent level.

Women's ideal number of children is also affected differently by female and male mortality. If female mortality increases from its mean in 1987 to its mean in 1998, women's ideal 
number of children is predicted to decrease with 0.381 , and the coefficient is statistically significant at the one per cent level. If instead male mortality increases from its mean in 1987 to its mean in 1998, women's ideal number of children is predicted to increase marginally, but the coefficient is not statistically different from zero. The difference between female and male mortality is statistically significant at the one per cent level (Table 3).

Men's ideal number of children, on the other hand, is more negatively affected by male than female mortality. An increase in male mortality from its 1987 to its 1998 mean decreases the stated ideal number of children by 0.150 children, while a similar increase in female mortality decreases it by 0.085 . The coefficient for male mortality is statistically significant at the one per cent level, but the one for female mortality and the difference between female and male mortality are not statistically different from zero.

\section{DISCUSSION AND CONCLUSION}

Understanding how HIV/AIDS affects childbearing in countries with high infection rates is of great interest, since the future course of fertility is likely to be a major determinant of economic development. This paper analyzes the impact of district prime-age mortality, a proxy for AIDS mortality, in rural Malawi on both actual fertility and women's and men's desired fertility, among women and men who provided a negative HIV test. The analysis considers the overall response of fertility to AIDS, but the focus is on differences in the response to mortality among prime-age women versus prime-age men.

We find that mortality has a positive overall impact on fertility among uninfected women: those living in districts with high prime-age mortality and HIV rates give birth to more children than those living in districts with low rates. The increase in fertility among the uninfected women is about $10 \%$ during the period analyzed, mid-1999 - mid-2004. However, the coefficient is only significant at the ten percent level. When HIV-positive women and 
those who refused to be tested are included in the sample, it is close to zero and insignificant. This is probably due to physiological effects of HIV/AIDS.

We also find that female mortality reduces actual fertility while male mortality increases it. The AIDS-induced increase in male mortality between 1987 and 1998 raised fertility by $18.5 \%$, while the increase in female mortality reduced fertility by $6.3 \%$. Moreover, when the desired number of children is modeled instead of actual births, own-sex mortality has a negative impact: women desire to have fewer children when female mortality is high and men desire to have fewer children when male mortality is high.

Our findings are consistent Soros (2006) and others who argue that adult mortality increases fertility. However, AIDS does not only increase mortality; other effects, such as the direct physical effect of the disease and the risk of giving birth to HIV-infected babies moderate the increase. And equally or more important, AIDS-induced mortality has strong gender-specific effects that ameliorate the impact of increased fertility.

Explaining why there are gender-specific effects is not straightforward, but they are consistent with lack of social security and pensions, which for a long time has been known to be a key motive for having children (Cain, 1981; Schultz, 1997). Moreover, children are expected to provide care for their elderly parents and help with household chores. When female mortality is high women might not expect to live to old age, reducing the need of future support from children. However, when male mortality is high there is a high risk that the husband dies early, i.e. of widowhood, and thus an increased need of support from children. The fertility response to increased female mortality can therefore differ from that of increased male mortality. The old-age security motive to have children is likely to be of greater concern for women than men in Malawi: they should expect to outlive their husbands by several years; there are fewer job opportunities for women; and some women risk losing 
their property when they become widows because of land grabbing (Arrehag et al., 2006). In Southern and Central Malawi, couples commonly live in the wife's village, i.e., in matrilineal societies, where women's right to land is not directly dependent on their husbands. Still, economic security is higher when the husband is alive. In other words, the old age security motive for having children should reduce the marginal benefit of children due to parents' own increased mortality risk. This interpretation is supported by the negative impact of own-sex mortality on both women's and men's ideal number of children

Since it is desirable that fertility decreases in Malawi, the high demand for children should be addressed. Our results suggest that women have many children for economic security reasons. Although requiring further study, introducing pensions that cover the great majority of the older population has the potential to substantially decrease fertility (Boldrin and Jones, 2002; Boldrin, et al., 2005; Holmquist, 2010). Since life expectancy is low in Malawi, the cost of pensions might be sustainable. Measures to increase women's economic independence, including land inheritance practices, might also reduce fertility. 
APPENDIX

Table A1: Individual-level summary statistics

\begin{tabular}{|c|c|c|c|c|}
\hline & \multicolumn{2}{|l|}{ Women } & \multicolumn{2}{|l|}{ Men } \\
\hline & Mean & Std. Err. & Mean & Std. Err. \\
\hline Births last 5 years & 0.974 & 0.870 & & \\
\hline Ideal number of children & 4.056 & 1.345 & 4.096 & 1.523 \\
\hline Age 15-19 & 0.200 & 0.400 & 0.200 & 0.400 \\
\hline Age $20-24$ & 0.236 & 0.425 & 0.179 & 0.384 \\
\hline Age 25-29 & 0.181 & 0.385 & 0.191 & 0.393 \\
\hline Age $30-34$ & 0.133 & 0.339 & 0.144 & 0.351 \\
\hline Age $35-39$ & 0.099 & 0.298 & 0.087 & 0.283 \\
\hline Age $40-44$ & 0.083 & 0.276 & 0.091 & 0.288 \\
\hline Age $45-49$ & 0.068 & 0.252 & 0.052 & 0.223 \\
\hline Age $50-54$ & & & 0.054 & 0.225 \\
\hline Prior births ( 5 years ago) & 2.220 & 2.611 & & \\
\hline Total number of births & 3.194 & 2.740 & 2.994 & 3.328 \\
\hline No or incomplete primary education & 0.260 & 0.439 & 0.117 & 0.321 \\
\hline Primary education & 0.641 & 0.480 & 0.678 & 0.467 \\
\hline Secondary education & 0.097 & 0.296 & 0.195 & 0.396 \\
\hline Higher education & 0.002 & 0.043 & 0.010 & 0.099 \\
\hline 1st wealth quintile & 0.203 & 0.402 & 0.150 & 0.357 \\
\hline 2nd wealth quintile & 0.227 & 0.419 & 0.236 & 0.425 \\
\hline 3rd wealth quintile & 0.238 & 0.426 & 0.256 & 0.437 \\
\hline 4th wealth quintile & 0.217 & 0.412 & 0.233 & 0.423 \\
\hline 5th wealth quintile & 0.115 & 0.319 & 0.124 & 0.330 \\
\hline Catholic & 0.779 & 0.415 & 0.786 & 0.410 \\
\hline Central African Presbyterian Church & 0.164 & 0.371 & 0.175 & 0.380 \\
\hline Anglican & 0.016 & 0.127 & 0.017 & 0.130 \\
\hline Seventh day adventist/Baptist & 0.061 & 0.239 & 0.058 & 0.234 \\
\hline Other Christian & 0.365 & 0.481 & 0.379 & 0.485 \\
\hline Muslim & 0.161 & 0.367 & 0.132 & 0.339 \\
\hline No religion & 0.012 & 0.107 & 0.026 & 0.159 \\
\hline Chewa & 0.314 & 0.464 & 0.323 & 0.468 \\
\hline Tumbuka & 0.098 & 0.297 & 0.098 & 0.297 \\
\hline Lomwe & 0.201 & 0.400 & 0.204 & 0.403 \\
\hline Tonga & 0.019 & 0.135 & 0.020 & 0.140 \\
\hline Yao & 0.160 & 0.366 & 0.134 & 0.341 \\
\hline Sena & 0.031 & 0.174 & 0.035 & 0.185 \\
\hline Nkonde & 0.008 & 0.088 & 0.010 & 0.099 \\
\hline Ngoni & 0.091 & 0.287 & 0.095 & 0.293 \\
\hline Other ethnicity & 0.079 & 0.269 & 0.082 & 0.274 \\
\hline
\end{tabular}

Source: Measure DHS (2010). 
Table A2: District-level variables summary statistics (rural areas)

\begin{tabular}{llllll}
\hline & Obs. & Mean & Std. dev. & Min & Max \\
\cline { 2 - 6 } Prime-age mortality & 27 & 0.017 & 0.008 & 0.007 & 0.036 \\
Female prime-age mortality & 27 & 0.014 & 0.007 & 0.006 & 0.031 \\
Male prime-age mortality & 27 & 0.019 & 0.010 & 0.007 & 0.041 \\
Pre-HIV fertility & 27 & 0.181 & 0.021 & 0.154 & 0.226 \\
\hline
\end{tabular}

Source: Measure DHS (2010) and data from 1998 Population and Census supplied by National Statistical Office, Zomba. 
Table A3: Original and cluster bootstrap-t statistics for selected specifications

\begin{tabular}{|c|c|c|c|c|c|c|c|}
\hline \multirow[t]{2}{*}{ Null-hypothesis } & \multirow{2}{*}{$\begin{array}{l}\text { Original } \\
\text { sample } \\
\text { statistic }\end{array}$} & \multicolumn{6}{|c|}{ Distribution of test-statistic from the cluster bootstrap } \\
\hline & & $\begin{array}{l}\text { 1st } \\
\text { percentile }\end{array}$ & $\begin{array}{l}\text { 5th } \\
\text { percentile }\end{array}$ & $\begin{array}{l}\text { 10th } \\
\text { percentile }\end{array}$ & $\begin{array}{l}\text { 90th } \\
\text { percentile }\end{array}$ & $\begin{array}{l}\text { 95th } \\
\text { percentile }\end{array}$ & $\begin{array}{l}\text { 99th } \\
\text { percentile }\end{array}$ \\
\hline \multicolumn{8}{|l|}{ Specification 1. Table 1} \\
\hline Age $20-24=0$ & 14.324 & -2.477 & -1.247 & -1.012 & 1.616 & 2.255 & 2.636 \\
\hline Age $25-29=0$ & 14.349 & -2.938 & -1.714 & -1.197 & 1.640 & 1.886 & 2.795 \\
\hline Age $30-34=0$ & 11.106 & -3.017 & -1.841 & -1.295 & 1.699 & 2.548 & 2.942 \\
\hline Age $35-39$ & 6.796 & -2.297 & -1.538 & -1.002 & 1.699 & 2.389 & 3.879 \\
\hline Age 40-44 & 0.738 & -2.023 & -1.462 & -0.970 & 1.375 & 1.701 & 2.814 \\
\hline Age $45-49$ & -2.026 & -2.321 & -1.675 & -1.414 & 1.282 & 1.781 & 2.616 \\
\hline Prior births & 1.915 & -2.913 & -1.757 & -1.381 & 1.368 & 1.702 & 2.436 \\
\hline Primary education & -0.313 & -1.930 & -1.561 & -1.318 & 0.879 & 1.032 & 2.691 \\
\hline Secondary education & -3.611 & -2.306 & -1.774 & -1.602 & 1.389 & 2.284 & 3.758 \\
\hline Higher education & -2.581 & -69.488 & -56.548 & -48.636 & 4.901 & 8.222 & 14.977 \\
\hline 2nd wealth quintile & -1.199 & -2.418 & -1.114 & -0.962 & 1.123 & 1.589 & 2.606 \\
\hline 3rd wealth quintile & -3.008 & -2.559 & -1.638 & -1.153 & 1.328 & 1.732 & 2.926 \\
\hline 4th wealth quintile & -2.227 & -2.292 & -1.365 & -1.079 & 1.583 & 2.047 & 2.998 \\
\hline 5th wealth quintile & -6.256 & -2.569 & -1.464 & -1.110 & 1.535 & 2.139 & 5.134 \\
\hline District fertility before HIV & 2.460 & -21.599 & -16.400 & -13.800 & 1.177 & 2.044 & 3.325 \\
\hline Adult mortality & 1.551 & -13.298 & -4.459 & -3.610 & 0.949 & 1.857 & 3.986 \\
\hline \multicolumn{8}{|l|}{ Specification 2. Table 1} \\
\hline Age $20-24$ & -3.159 & -2.450 & -1.476 & -1.212 & 1.133 & 1.502 & 1.779 \\
\hline Age 25-29 & -1.391 & -2.038 & -1.402 & -0.905 & 1.003 & 1.615 & 2.075 \\
\hline Age $30-34$ & -2.058 & -1.784 & -1.293 & -0.908 & 1.196 & 1.470 & 2.283 \\
\hline Age 35-39 & -1.664 & -1.492 & -0.939 & -0.611 & 1.340 & 1.977 & 2.768 \\
\hline Age $40-44$ & -1.991 & -2.127 & -1.178 & -0.850 & 1.245 & 1.536 & 2.340 \\
\hline Age $45-49$ & -2.374 & -1.658 & -1.128 & -0.815 & 1.311 & 1.776 & 2.996 \\
\hline Living children & 2.668 & -2.196 & -1.513 & -1.250 & 0.851 & 1.188 & 1.521 \\
\hline Primary education & -0.309 & -1.469 & -1.240 & -1.049 & 0.738 & 1.061 & 1.787 \\
\hline Secondary education & -0.929 & -1.741 & -1.296 & -1.122 & 0.950 & 1.253 & 1.478 \\
\hline Higher education & -1.581 & -4.181 & -2.438 & -1.967 & 5.975 & 7.305 & 9.949 \\
\hline 2nd wealth quintile & 1.041 & -1.935 & -1.313 & -1.030 & 1.217 & 1.351 & 1.904 \\
\hline 3rd wealth quintile & -0.224 & -2.163 & -1.559 & -1.099 & 0.974 & 1.410 & 2.911 \\
\hline 4th wealth quintile & 1.083 & -2.265 & -1.701 & -1.319 & 0.964 & 1.363 & 2.150 \\
\hline 5th wealth quintile & -1.576 & -2.167 & -1.466 & -0.956 & 1.198 & 2.421 & 4.149 \\
\hline District fertility before HIV & -1.262 & -2.297 & -1.219 & -0.732 & 2.144 & 2.584 & 3.346 \\
\hline Adult mortality & -2.398 & -3.100 & -0.888 & -0.592 & 4.731 & 5.223 & 14.110 \\
\hline \multicolumn{8}{|l|}{ Specification 3. Table 1} \\
\hline Age $20-24$ & -0.349 & -1.532 & -1.147 & -1.038 & 1.072 & 1.589 & 2.123 \\
\hline Age $25-29$ & 0.544 & -2.189 & -1.653 & -1.073 & 1.363 & 1.586 & 2.286 \\
\hline Age $30-34$ & 2.141 & -2.177 & -1.306 & -1.031 & 0.985 & 1.298 & 1.546 \\
\hline Age $35-39$ & 2.779 & -2.070 & -1.228 & -0.870 & 0.985 & 1.130 & 1.606 \\
\hline Age $40-44$ & 1.722 & -1.659 & -1.224 & -0.933 & 0.988 & 1.355 & 2.201 \\
\hline Age 45-49 & 1.196 & -2.454 & -1.637 & -0.935 & 1.067 & 1.168 & 1.906 \\
\hline
\end{tabular}




$\begin{array}{llllllll}\text { Age 50-54 } & 1.289 & -2.320 & -1.658 & -1.178 & 0.991 & 1.104 & 1.581 \\ \text { Table A3 continued } & & & & & & & \\ \text { Living children } & 7.567 & -1.908 & -1.370 & -1.018 & 1.130 & 1.444 & 1.985 \\ \text { Primary education } & 0.487 & -1.735 & -1.361 & -1.196 & 1.068 & 1.374 & 1.651 \\ \text { Secondary education } & -2.416 & -2.342 & -1.339 & -1.021 & 0.901 & 1.140 & 2.282 \\ \text { Higher education } & -1.625 & -1.715 & -1.070 & -0.713 & 1.335 & 1.528 & 3.132 \\ \text { 2nd wealth quintile } & -2.567 & -1.675 & -1.326 & -0.962 & 1.111 & 1.538 & 2.378 \\ \text { 3rd wealth quintile } & -2.311 & -1.748 & -1.365 & -0.917 & 1.148 & 1.411 & 1.818 \\ \text { 4th wealth quintile } & -3.663 & -2.344 & -1.329 & -0.863 & 1.145 & 1.442 & 1.728 \\ \text { 5th wealth quintile } & -5.861 & -1.226 & -0.963 & -0.783 & 1.285 & 1.714 & 2.427 \\ \text { District fertility before HIV } & -1.151 & -2.648 & -1.821 & -1.331 & 1.297 & 1.476 & 2.274 \\ \text { Adult mortality } & -1.960 & -3.424 & -1.896 & -1.183 & 1.352 & 2.181 & 3.611 \\ \text { Specification 1. Table 3 } & & & & & & & \\ \text { Female adult mortality } & -0.739 & -2.605 & -1.114 & -0.701 & 3.681 & 4.297 & 6.862 \\ \text { Male adult mortality } & 2.200 & -9.164 & -4.789 & -3.841 & 0.474 & 1.126 & 2.321 \\ \text { Female = male } & -1.486 & -2.339 & -1.124 & -0.536 & 4.282 & 5.027 & 8.526 \\ \text { Specification 2. Table 3 } & & & & & & & \\ \text { Female adult mortality } & -3.500 & -2.095 & -1.212 & -0.854 & 4.771 & 7.713 & 10.074 \\ \text { Male adult mortality } & 0.124 & -6.139 & -3.475 & -2.547 & 1.560 & 2.187 & 3.266 \\ \text { Female = male } & -2.425 & -2.213 & -1.290 & -0.901 & 5.653 & 7.736 & 11.414 \\ \text { Specification 3. Table 3 } & & & & & & & \\ \text { Female adult mortality } & -0.702 & -2.653 & -2.006 & -1.684 & 1.717 & 2.105 & 3.940 \\ \text { Male adult mortality } & -3.210 & -3.014 & -1.751 & -1.402 & 1.133 & 1.448 & 1.740 \\ \text { Female = male } & 0.138 & -2.231 & -1.770 & -1.424 & 1.498 & 1.836 & 3.440\end{array}$




\section{REFERENCES}

Ahuja, A., B. Wendell, and E. Werker (2009), "Male Circumcision and AIDS: The Macroeconomic Impact of a Health Crisis", Harvard Business School Working Paper No. 07025 .

Ainsworth, M., D. Filmer, and I. Semali (1998),'The Impact of AIDS Mortality on Individual Fertility: Evidence from Tanzania" in From Death to Birth: Mortality Decline and Reproductive Change, Montgomery, M., and B. Cohen (eds.), National Academies Press.

Arrehag L., Durevall, D., Sjöblom M., de Vylder, S. (2006) The impact of HIV/AIDS on Livelihoods, Poverty and the Economy of Malawi Stockholm, Sida Studies no. 18.

Bertrand, M., Duflo, E., Mullainathan, S. (2004), "How Much Should We Trust Differencein-Difference Estimates?”, Quarterly Journal of Economics, 119(1):249-275.

Boldrin, M. and L. E. Jones (2002) "Mortality, Fertility, and Saving in a Malthusian Economy", Review of Economic Dynamics, 5(4), 775-814.

Boldrin, M., De Nardi M., Jones, L.E. (2005) "Fertility and Social Security" NBER Working Paper no. 11146.

Bollen, K.A., J.L. Glanville, and G. Stecklov (2007), "Socio-economic status, permanent income, and fertility: A latent-variable approach", Population Studies, 61(1):15-34.

Boucekkine, R., R. Desbordes and H. Latzer, (2009) "How do epidemics induce behavioral changes?" Journal of Economic Growth, 14(3):233-264.

Cain, M. (1981) "Risk and Insurance: Perspectives on Fertility and Agrarian Change in India and Bangladesh" Population and Development Review, 7(3), 435-474.

Cameron, A.C., Gelbach, J.G., Miller, D.L. (2008), "Bootstrap-Based Improvements for Inference with Clustered Errors", Review of Economics and Statistics, 90(3):414-427.

Chimbwete, C., S.C. Watkins, and E.M. Zulu (2005), "The Evolution of Population Policies in Kenya and Malawi”, Population Research and Policy Review 24(1):85-106.

Delavande, A. and H.P. Kohler (2009), "Subjective Mortality Expectations and HIV/AIDS in Malawi”, Demographic Research, 20(article 31): 817-874.

Doctor, H.V., and A.A. Weinreb (2003), "Estimation of AIDS Adult Mortality by Verbal Autopsy in Rural Malawi” AIDS 17(17): 2509-2513.

Durevall, D. and A. Lindskog (2011), "Uncovering the Impact of the HIV Epidemic on Fertility in Sub-Saharan Africa: the Case of Malawi”, Journal of Population Economics. 24(2): 629-55.

Fink, G., and S. Linnemayr (2009), "HIV does Matter for Fertility: Human Capital, Mortality and Family Size", unpublished, Harvard School of Public Health. 
Fortson, J. (2009), "HIV/AIDS and Fertility", American Economic Journal: Applied Economics, 1(3): 170-194.

Glick, P., and D. Sahn (2008), “Are Africans Practicing Safer Sex? Evidence from Demographic and Health Surveys for Eight Countries", Economic Development \& Cultural Change, 56(2): 397-439.

Grieser, M., J. Gittelsohn, A.V. Shankar, and T. Koppenhaver (2001), "Reproductive Decision Making and the HIV/AIDS Epidemic in Zimbabwe", Journal of Southern African Studies 27(2): 225-243.

Holmqvist, G. (2010) "Fertility impact of social transfers in Sub-Saharan Africa: What about pensions" BWPI working papers 119, Brooks World Poverty Institute, Manchester.

Juhn, C., Kalemli-Ozcan, S., Turan, B. (2009) "HIV and Fertility in Africa: First-Evidence from Population Based Surveys" NBER working paper 12181 (revised).

Kalemli-Ozcan, S. (2012), "AIDS, "reversal" of the demographic transition and economic development: evidence from Africa," Journal of Population Economics, 25(3): 871-897.

Kalemli-Ozcan, S. and B. Turan (2011), "HIV and Fertility Revisited", Journal of Development Economics 96(1):61-65.

Kohler, I. V., HP Kohler, P. Anglewicz, and J. R. Behrman. 2011. "Intergenerational Transfers in the Era of HIV/AIDS: Evidence from Rural Malawi." PSC Working Paper Series, PSC 11-03, University of Pennsylvania.

Lewis, J. C., C. Ronsmans, A. Ezeh, and S. Gregson (2004), “The Population Impact of HIV on Fertility in Sub-Saharan Africa", AIDS, 18 (suppl 2): S35-S43.

Lorentzen, P., J. McMillan, and R. Wacziarg (2008), "Death and Development”, Journal of Economic Growth, 13(2): 81-124.

Magadi M. A., and A. Agwanda (2010). "Investigating the association between HIV/AIDS and recent fertility patterns in Kenya" Social Science \& Medicine, 71(2): 335-344.

Malawi Government (2007) "Malawi HIV and AIDS Monitoring and Evaluation Report 2007” Office of the President and Cabinet, Lilongwe.

Malawi Government (2012) “2012 Global AIDS Response progress Report: Malawi Country Report for 2010 and 2011” Lilongwe.

Measure DHS (2004) Malawi Demographic and Health Survey Dataset 2004, available at http://www.measuredhs.com/

Morah, E. U. (2007) “Are People Aware of Their HIV-positive Status Responsible for Driving the Epidemic in Sub-Saharan Africa? The Case of Malawi" Development Policy Review, 25(2), 215-242.

Moulton, B.R. (1990), "An Illustration of a Pitfall in Estimating the Effects of Aggregate Variables on Micro Units”, Review of Economics and Statistics, 72(2): 334-338. 
Noël-Miller, C. M. (2003)"Concern regarding the HIV/AIDS epidemic and individual childbearing, evidence from rural Malawi” Demographic Research 1(10) 318-326.

NSO (National Statistical Office) (2010a) Thematic report on spatial distribution and urbanization, Population and Housing Census 2008, Zomba, available at http://www.nso.malawi.net/.

NSO (2010b) Thematic report on fertility, Population and Housing Census 2008, Zomba, available at http://www.nso.malawi.net/.

NSO and Macro International (1994) Malawi Demographic and Health Survey 1992,

National Statistical Office, Zomba, Malawi and ICF Macro, Calverton, Maryland, USA.

NSO and ORC Macro (2001) Demographic and Health Survey 2000, Final report, National Statistical Office, Zomba, Malawi and ICF Macro, Calverton, Maryland, USA.

NSO and OCR Macro (2005), Malawi: DHS 2004, Final report, National Statistical Office, Zomba, Malawi and ICF Macro, Calverton, Maryland, USA.

NSO and OCR Macro (2011), Malawi DHS, 2010, Final report, National Statistical Office, Zomba, Malawi and ICF Macro, Calverton, Maryland, USA.

NSO and UNICEF (2008) Multiple Indicator Survey 2006: Malawi, Zomba.

Ntozi, J. (2002) "Impact of HIV/AIDS on Fertility in Sub-Saharan Africa" African Population Studies, 17(1): 103-124.

Nugent, J.B. (1985) "The Old-Age Security Motive for Fertility" Population and Development Review, 11( 1): 75-97.

Oster, E. (2010) "Estimating HIV Prevalence and Incidence in Africa from Mortality Data," The B.E. Journal of Economic Analysis \& Policy 10(1), Article 80.

Oster, E. (2012) "HIV and sexual behavior change: Why not Africa?" Journal of Health Economics, 31(1): 35-49.

Pörtner, C. (2001) “Children as Insurance” Journal of Population Economics, 14(1): 119-136

Setel, P. (1995) "The effects of HIV and AIDS on fertility in East and Central Africa" Health Transition Review" 5 (Supplement) :179-189.

Schultz, P. (1997), "Demand for Children in Low Income Countries" Chap. 8 in Handbook of Population and Family Economics, in Rosenzweig, M. and O. Stark (eds.), Part A, Elsevier, Amsterdam.

Shapira, G. (2010), "How Subjective Beliefs About HIV Infection Affect Life-Cycle Fertility: Evidence from Rural Malawi," November 2010. Unpublished manuscript.

Soares R.R. (2005), "Mortality Reductions, Educational Attainment, and Fertility Choice", American Economic Review 95(3): 580-601. 
Soares R.R. (2006), "The Effect of Longevity on Schooling and Fertility: Evidence from the Brazilian Demographic and Health Survey", Journal of Population Economics, 19(1): 71-97.

Ueyama, M., and F. Yamauchi (2009), "Marriage Behavior Response to Prime-age Adult Mortality - Evidence from Malawi”, Demography 46(1): 43-63.

UNAIDS, (2010) Global Report: UNAIDS Report on the global AIDS epidemic 2010. Geneva. Available at http://www.unaids.org/GlobalReport/Global report.htm.

UNAIDS, (2012) HIV estimates with uncertainty bounds, available at http://www.unaids.org/en/dataanalysis/knowyourepidemic/

UNGASS (2010) "Malawi HIV and AIDS Monitoring and Evaluation Report: 2008-2009" Country Progress Report, National AIDS Council, Lilongwe.

UNICEF (2010) Child Mortality Report 2010, United Nations Inter-agency Group for Child Mortality Estimation, Geneva.

United Nations (2002) "HIV/AIDS and Fertility in Sub-Saharan Africa: A Review of the Research Literature” Department of Economic and Social Affairs, UN Secretariat, ESA/P/WP.174.

Young, A. (2005), "The Gift of Dying: The Tragedy of AIDS and the Welfare of Future African Generations", Quarterly Journal of Economics 120(2): 423-466.

Young, A. (2007), "In Sorrow to Bring Forth Children: Fertility amidst the Plague of HIV", Journal of Economic Growth 12(4): 283-327. 
Table 1: Total effect of prime-age mortality on fertility behavior - Ordered probit

\begin{tabular}{|c|c|c|c|c|c|}
\hline & $\begin{array}{c}\text { Births } \\
1999-2004\end{array}$ & $\begin{array}{l}\text { Women's ideal } \\
\text { number of } \\
\text { children }\end{array}$ & $\begin{array}{l}\text { Men's ideal } \\
\text { number of } \\
\text { children }\end{array}$ & $\begin{array}{c}\text { Births } \\
\text { 1999-2004 } \\
\text { full sample }\end{array}$ & $\begin{array}{c}\text { Births } \\
\text { 1999-2004, } \\
\text { full sample }\end{array}$ \\
\hline & (1) & $(2)$ & (3) & (4) & $(5)$ \\
\hline Age $20-24$ & $1.495 * * *$ & $-0.201 * * *$ & -0.038 & $1.571 * * *$ & $1.503 * * *$ \\
\hline Age $25-29$ & $1.559 * * *$ & $-0.123^{*}$ & 0.064 & $1.591 * * *$ & $1.560 * * *$ \\
\hline Age $30-34$ & $1.225 * * *$ & $-0.250 * * *$ & $0.290 * * *$ & $1.213 * * *$ & $1.211 * * *$ \\
\hline Age 35-39 & $1.031 * * *$ & $-0.257 * * *$ & $0.396 * * *$ & $0.878 * * *$ & $1.006 * * *$ \\
\hline Age $40-44$ & 0.155 & $-0.285^{* *}$ & $0.293 * *$ & 0.201 & 0.139 \\
\hline Age $45-49$ & $-0.395 * *$ & $-0.401 * * *$ & $0.242 * *$ & $-0.466^{*}$ & $-0.414 * *$ \\
\hline Age $50-54$ & & & $0.177 * *$ & & \\
\hline Prior births & $0.0368 * *$ & & & $0.063 * * *$ & $0.041 * *$ \\
\hline Living children & & $0.068 * * *$ & $0.133 * * *$ & & \\
\hline Primary education & -0.0188 & -0.0193 & 0.041 & -0.026 & -0.028 \\
\hline Secondary education & $-0.359 * * *$ & -0.111 & $-0.268 * * *$ & $-0.364 * * *$ & $-0.334 * *$ \\
\hline Higher education & -1.662 & -0.817 & $-0.467 * *$ & $-0.716^{*}$ & -1.728 \\
\hline 2nd wealth quintile & $-0.106 * *$ & $0.0736 * *$ & $-0.218 * * *$ & -0.003 & $-0.097 *$ \\
\hline 3rd wealth quintile & $-0.187 * * *$ & -0.0189 & $-0.186^{* * *}$ & -0.045 & $-0.173 * * *$ \\
\hline 4th wealth quintile & $-0.212 * *$ & $0.0882 *$ & $-0.373 * * *$ & $-0.134 * * *$ & $-0.194 * *$ \\
\hline 5th wealth quintile & $-0.475 * * *$ & $-0.197 * *$ & $-0.487 * * *$ & $-0.312 * * *$ & $-0.471 * * *$ \\
\hline Pre-HIV district fertility & $9.863 * *$ & $-4.524 * *$ & -3.798 & 1.407 & \\
\hline Prime-age mortality & $13.250 *$ & $-21.130 * *$ & $-17.600 * *$ & -3.611 & -5.500 \\
\hline Observations & 2143 & 1925 & 1785 & 10031 & 2149 \\
\hline
\end{tabular}


Table 2: Predicted effect of the HIV/AIDS epidemic on fertility - effect of adult mortality increasing from its 1987 mean to its 1998 mean (based on specification 1 in Table 1)

With HIV/AIDS Without HIV/AIDS Change

(mortality at its 1998 (mortality at its 1987

mean)

mean)

\begin{tabular}{llll}
\hline Number of births 1999-2004 & 0.8905 & 1.0016 & 0.1108
\end{tabular}

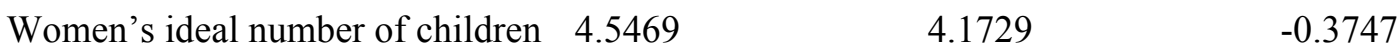

$\begin{array}{llll}\text { Men's ideal number of children } & 4.2848 & 4.0456 & -0.239\end{array}$ 
Table 3: Effect of female- respectively male adult mortality on fertility behavior (among HIV negative people) - Ordered probit coefficients

\begin{tabular}{|c|c|c|c|}
\hline & $\begin{array}{c}\text { Births } \\
1999-2004\end{array}$ & $\begin{array}{l}\text { Women's ideal } \\
\text { number of } \\
\text { children }\end{array}$ & $\begin{array}{l}\text { Men's ideal } \\
\text { number of } \\
\text { children }\end{array}$ \\
\hline & (1) & $(2)$ & (3) \\
\hline Female adult mortality & $-8.441^{*}$ & $-26.43 * * *$ & -7.583 \\
\hline Male adult mortality & $17.37^{* *}$ & 0.775 & $-9.676 * * *$ \\
\hline \multicolumn{4}{|l|}{ Tests of equality of coefficients } \\
\hline Female- minus male adult mortality & $-25.807 * *$ & $-27.210 * * *$ & 2.092 \\
\hline Observations & 2143 & 1925 & 1785 \\
\hline \multicolumn{4}{|c|}{$\begin{array}{l}\text { All estimations include age dummies, education dummies, household wealth dummies, religion dummies, } \\
\text { ethnicity dummies, ordered probit cut-points (four in specification } 1 \text { and nine in specifications } 2 \text { and } 3 \text { ), and pre- } \\
\text { HIV district fertility. Specification also } 1 \text { includes the number of prior births, and specifications } 2 \text { and } 3 \text { the } \\
\text { number of living children. Estimations have been done with survey weights, and standard errors have been } \\
\text { clustered at the district level. } \\
*=\text { significant at the } 10 \% \text { level, } * *=\text { significant at the } 5 \% \text { level, } * * *=\text { significant at the } 1 \% \text { level, using a cluster } \\
\text { bootstrap-t procedure. }\end{array}$} \\
\hline
\end{tabular}


Table 4: Predicted effects of the HIV epidemic induced increase in female and male mortality on fertility among HIV negative people

\begin{tabular}{|c|c|c|c|c|}
\hline & & $\begin{array}{l}\text { Without HIV } \\
\text { (mortality at its } \\
1987 \text { mean) }\end{array}$ & $\begin{array}{l}\text { With HIV } \\
\text { (mortality at its } \\
1998 \text { mean) }\end{array}$ & Change \\
\hline \multirow{3}{*}{$\begin{array}{l}\text { Actual births } \\
1999-2004\end{array}$} & Female mortality rise & 0.892 & 0.835 & -0.056 \\
\hline & Male mortality rise & 0.892 & 1.056 & 0.165 \\
\hline & Both female and male mortality rise & 0.892 & 0.998 & 0.106 \\
\hline \multirow{3}{*}{$\begin{array}{l}\text { Women's } \\
\text { ideal } \\
\text { number of } \\
\text { births }\end{array}$} & Female mortality rise & 4.547 & 4.166 & -0.381 \\
\hline & Male mortality rise & 4.547 & 4.563 & 0.016 \\
\hline & Both female and male mortality rise & 4.547 & 4.181 & -0.367 \\
\hline \multirow{3}{*}{$\begin{array}{l}\text { Men's ideal } \\
\text { number of } \\
\text { children }\end{array}$} & Female mortality rise & 4.285 & 4.199 & -0.085 \\
\hline & Male mortality rise & 4.285 & 4.135 & -0.150 \\
\hline & Both female and male mortality rise & 4.285 & 4.052 & -0.234 \\
\hline
\end{tabular}

